\title{
Development and study of the model for epidemic spread
}

\author{
Anastasiya V. Ivanova ${ }^{1}$, Anna S. Sazonova ${ }^{I}$, Aleksandr A. Kuzmenko ${ }^{1}$ and Lyudmila B. \\ Filippova $^{1}$
}

${ }^{1}$ Bryansk State Technical University, Bryansk, 241035, Russia

\begin{abstract}
The paper is devoted to the analysis and research of the epidemiological situation in the Bryansk region caused by COVID-19 virus. The main points of the development and testing of the simulation model of epidemic spread are investigated. An algorithm for modeling the epidemiological situation is proposed, an optimization experiment is conducted that gives realistic values based on historical data, and appropriate conclusions are made. The proposed integrated approach allows to reduce the money and time spent on conducting experiments, and also allows to predict the dynamics of coronavirus development in the given region to work out the strategy of health services by using information technologies such as methods of systems simulation.
\end{abstract}

\section{Keywords}

COVID-19, pandemic, coronavirus, simulation, epidemic spread model

\section{Introduction}

The most relevant and powerful way to study processes and objects in the real world is mathematical modeling. It is used in situations where there are difficulties in studying the elements and processes of the area under consideration, as well as when it is impossible to conduct experiments. Modeling process significantly reduces the cost and simplifies the design and optimization of systems. One of the areas where the process of conducting research is quite difficult is epidemiology. The issues of studying the spread of diseases and infections are relevant for the entire society. Today, one of the infectious diseases that has covered the world is COVID-19, which urgency is justified by the pandemic status.

The development of a model for COVID-19 epidemic spread is aimed at studying the infectious disease and predicting its transmission.

The object of research in this work is COVID-19 disease with a predominant lung damage.

The subject under study is the application of simulation modeling to predict the situation of a pandemic caused by COVID-19 virus.

The aim of the study is to provide a methodological justification for the use of information systems to create a model for COVID-19 epidemic spread.

The main problem of epidemiology is the high cost of research, the waste of a large amount of time and the difficulty of predicting the dynamics of the infection spread. Modeling will help speed up and simplify the research process. The use of information technologies in this area marks a huge step forward in comparison with the classical methods.

The designed models can be used for research purposes: to predict the nature of the epidemic process and to develop a strategy for health services.

The main elements of the epidemiological process are presented using the concept of ratios, formulas, equations, etc.

III International Workshop on Modeling, Information Processing and Computing (MIP: Computing-2021), May 28, 2021, Krasnoyarsk, Russia

EMAIL: libv88@yandex.ru (Anastasiya Ivanova); asazonova@list.ru (Anna Sazonova); alex-rf-32@yandex.ru (Aleksandr Kuzmenko), libv88@mail.ru (Lyudmila Filippova)

ORCID: 0000-0003-2089-5932 (Anna Sazonova); 0000-0002-3529-7575 (Aleksandr Kuzmenko); 0000-0002-1894-2739 (Lyudmila Filippova)

(C) 2021 Copyright for this paper by its authors.

CEUR Workshop Proceedings (CEUR-WS.org) 
The following stages of making the model are formulated [1]:

- collection of data on the epidemiological process and formulation of the model structure based on them;

- mathematical interpretation of the formulated model;

- $\quad$ search for a number of variants of the epidemiological process under different conditions on a computer

Such population models are based on information about the relation of people with the infection, as well as people with each other.

A common" individual-to-infection model " is the SEIR model, where finite automata are:

- $\quad$ S-susceptible, uninfected;

- $\quad$ E-exposed;

- $\quad$ I- infectious = patients;

- $\quad$ R-recovered $=$ immune.

Based on the above initial data, a model is constructed that divides the population into groups corresponding to the states of the finite automaton.

In the field of epidemiological diseases spread, it is quite logical to use a system and dynamic model. This method is supported by AnyLogic simulation environment, which was chosen as a tool for developing the model and conducting experiments.

System dynamics is a method of analyzing complex systems, which examines their behavior over time, as well as the dependencies of system elements. For example, we study cause-and-effect relations, reaction delays, the influence of the environment, and so on. This method is mainly used for the development of long-term strategic models [2].

It is assumed that:

- a system is modeled that determines its own behavior based on the input data of SEIR model;

- feedback loops are identified that balance or reinforce data;

- flows and storages are identified that affect the feedback loops.

The state of the system is characterized by storage devices, and the power of influence is set by the flows between them [3].

On December 17th,2020, the region is on the 38th position according to coronavirus rate.

A large group of patients $(36.7 \%)$ are unemployed citizens and pensioners, $17.4 \%$ are office workers, $10.2 \%$ are health workers, $7.1 \%$ - employees in the field of education, $7 \%$ - industrial enterprises employees.

Among the age groups, the highest number of cases is between the ages of 49 and 64 .

Statistics:

- $\quad$ population of the Bryansk region is $1,192,491$;

- total coronavirus cases - 20,321;

- $\quad$ total deaths - 169 ;

- $\quad$ total recovered $-18,214$;

- mortality $-0.8 \%$;

- transmission rate is -1.21 .

The statistics of the epidemiological situation in the Bryansk region on December 17th,2020 are shown in Figure 1. [4,5]

\section{Development of a model of the epidemic spread in AnyLogic}

To study the epidemiological situation, a pandemic caused by COVID-19 virus was selected in the Bryansk region. The main task of the study is to construct a model that helps to study the spread of the infectious disease among the population (1,192,491 people).

The following situation is considered:

- initially 1 person is infected, the rest are susceptible to the infection;

- during the disease, 1 person on average has contact with others with the intensity of 1.21.

The probability of virus transmission is 0.7 ;

- the incubation period after being infected is 14 days; 


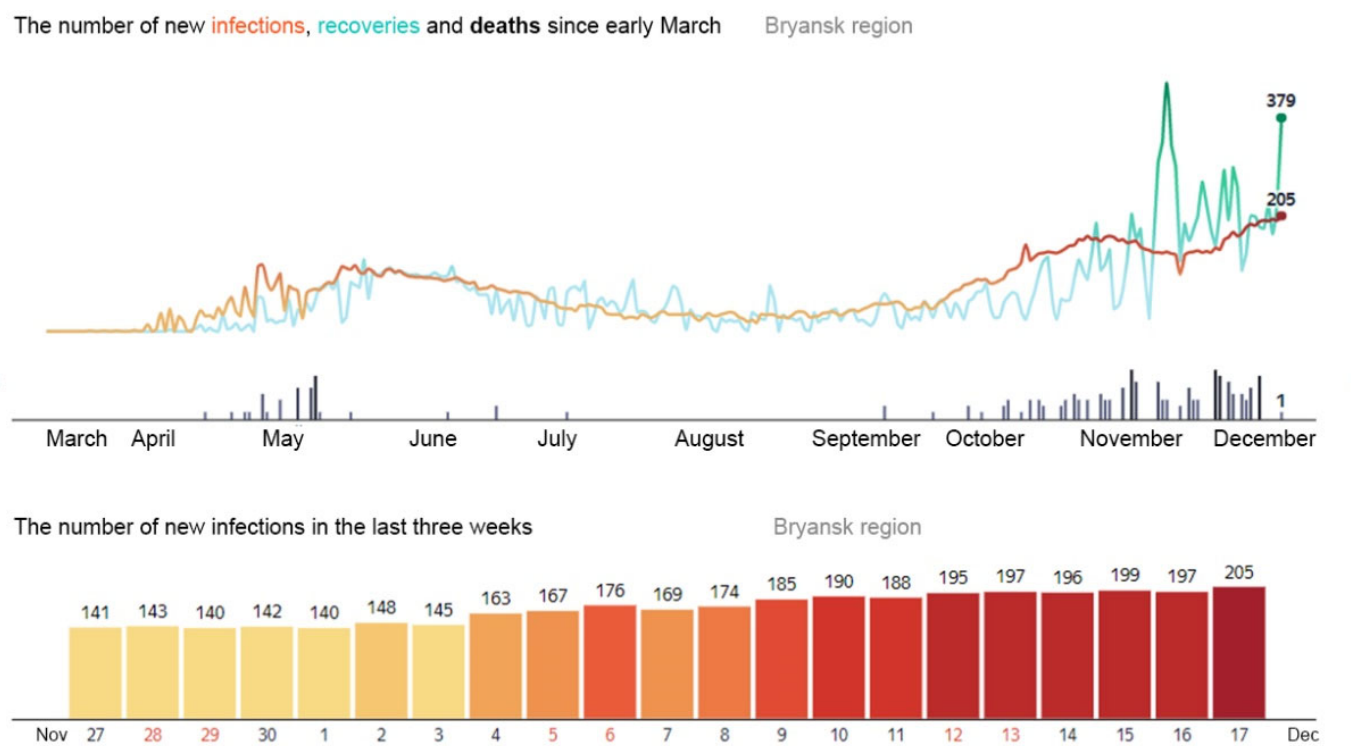

Figure 1. Epidemiological situation in the Bryansk region at the end of December 2020

- the incubation period after being infected is 14 days;

- the duration after the incubation period (the time when a person can infect others) is 21 days;

- $\quad$ the mortality rate due to the disease is 0.8 ;

- recovered individuals are immune.

Based on SEIR model, the following categories of people are distinguished that are important for the process under study:

- Susceptible - susceptible to infection (have not yet been infected with the virus).

- Exposed - people who are in the latent stage of infection (infected, but not yet able to infect others).

- Infectious - people in the active stage of infection (can infect other people).

- Recovered - the recovered part of the population.

The data storage media that are the system states correspond to the selected categories of people of the generally accepted SEIR model. In other words, each storage device corresponds to a certain stage of the disease [6]:

$$
\text { Susceptible } \rightarrow \text { Exposed } \rightarrow \text { Infectious } \rightarrow \text { Recovered }
$$

Based on the collected information provided in paragraphs 1.2 and 2.1, the main parameters of COVID-19 virus were identified as the following:

- TotalPopulation (total number of the population) $=1192491$

- $\quad$ Infectivity $=0.7$

- $\quad$ ContactRateInfectious (rate of epidemic spread) $=1.21$

- AverageIncubationTime (average incubation period) $=14$

- AveragelllnessDuration (average desease duration) $=21$

- $\quad$ Fatality (mortality rate) $=0.8$

To calculate the dependencies between the storage devices, flows are introduced that characterize the strength of parameter changes. Flows are calculated using formulas.

Formula for flow ExposedRate is the following:

$$
\frac{\text { Infectious } * \text { ContactRateInfectious } * \text { Infectivity } * \text { Susceptible }}{\text { TotalPopulation }}
$$

Formula for flow InfectiousRate is:

$$
\frac{\text { Exposed }}{\text { AverageIncubationTime }}
$$


Formula for flow RecoveredRate is:

$$
\frac{\text { Infectious }}{\text { AverageIllnessDuration }}
$$

Formula for flow DeadRate is:

$$
\frac{\text { Infectious } * \text { Fatality }}{\text { AverageIllnessDuration }}
$$

After creating all the links and the specified formulas, the simulated flow and storage diagram looks like this in Figure 2.

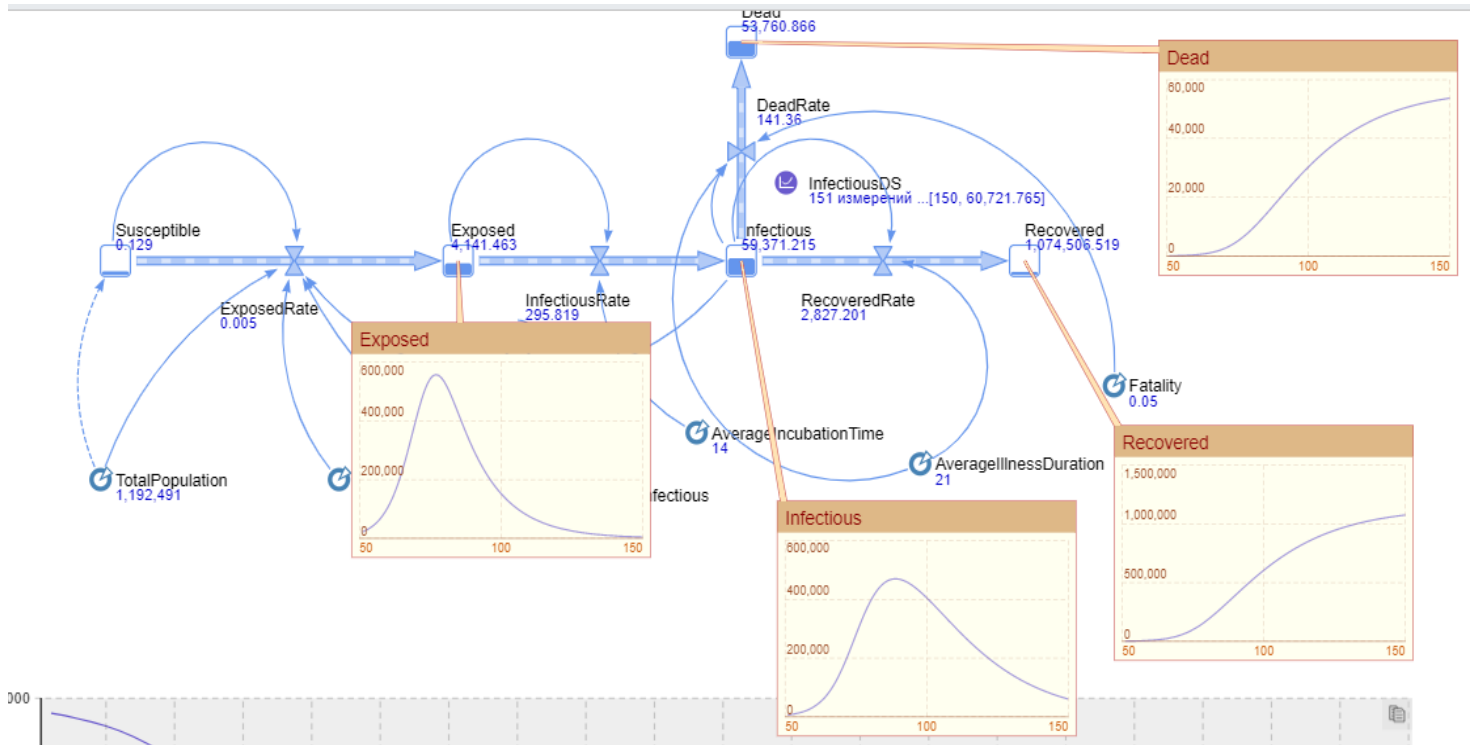

Figure 2. Diagram of flows and storage devices

A time graph (Figure 3) and a pie chart (Figure 4) were selected to visualize the data of the epidemic spread model.

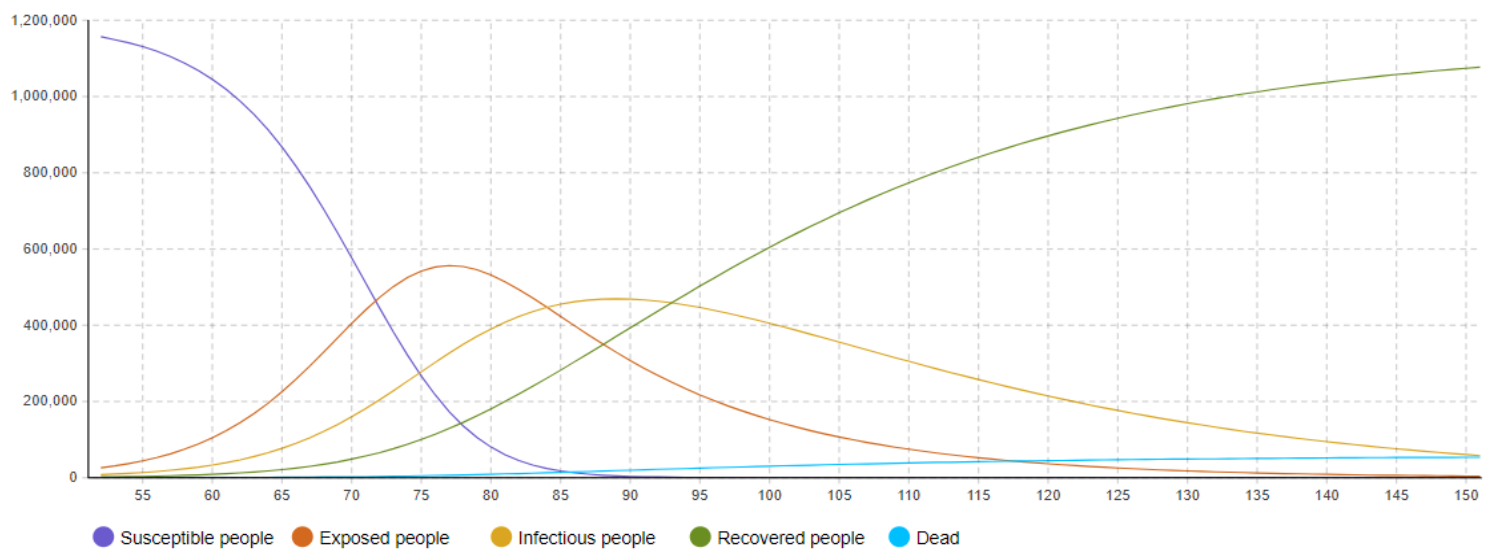

Figure 3. Time graph of the model 


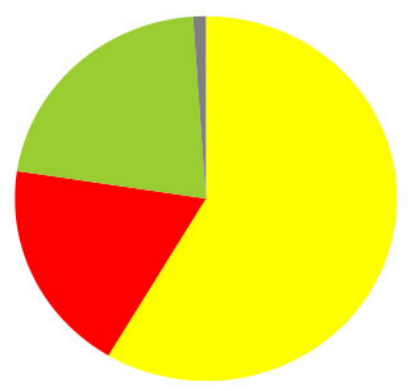

Susceptible $578,651.68(59 \%)$

Infectious 186,782.81 (19\%)

Recovered $212,655.37(22 \%)$

Dead $10,632.77(1 \%)$

Figure 4. Model pie-chart

The time graph shows the changes in the data sets over time.

The pie chart consists of circle sectors combined into one component. The sectors are proportional to the values of the corresponding data.

For the purpose of convenience, the model has sliders - controllers that allow to adjust the values. By changing the infectivity rate and the spread rate, you can use the sliders to assess the impact of these changes on the behavior of the simulated system.

A complete functioning model of the epidemic spread is shown in Figure 5.

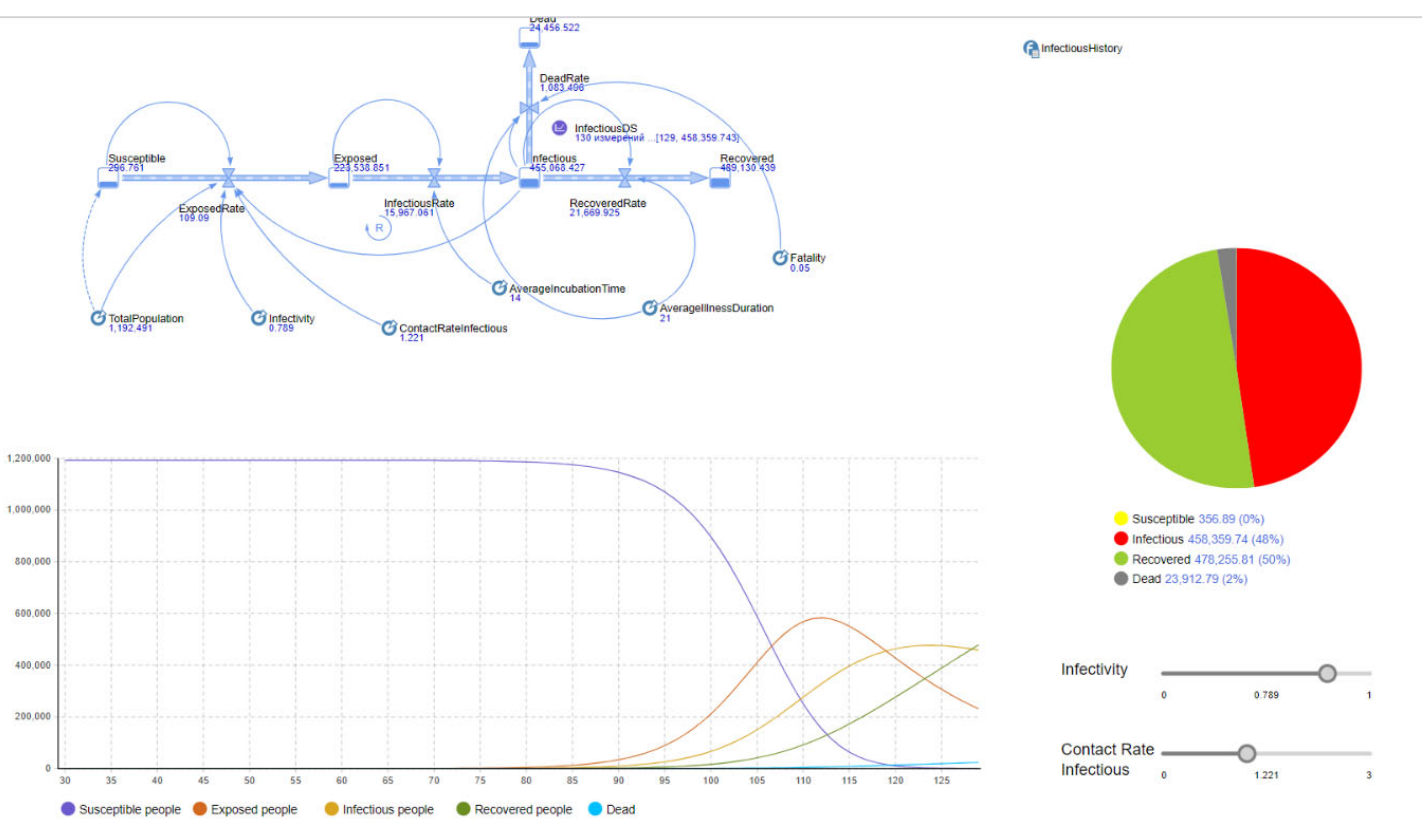

Figure 5. Epidemic spread model with visualization and control elements

\section{Experiment of parameters variation}

Using the experiment of varying the parameters it is possible to analyze how the dynamics of the epidemic spread changes at different values of the intensity of contacts between people. This method is used to perform a series of runs of the research parameters, sequentially selecting a certain combination of values for each [6].

In the experiment the parameter Contact Rate will vary in the range from the minimum value of 0.3 to the maximum value of 1 in increments of 0.1 . The result of the experiment is shown in Figure 6. 


\section{Epidemic1 : ContactRateVariation}

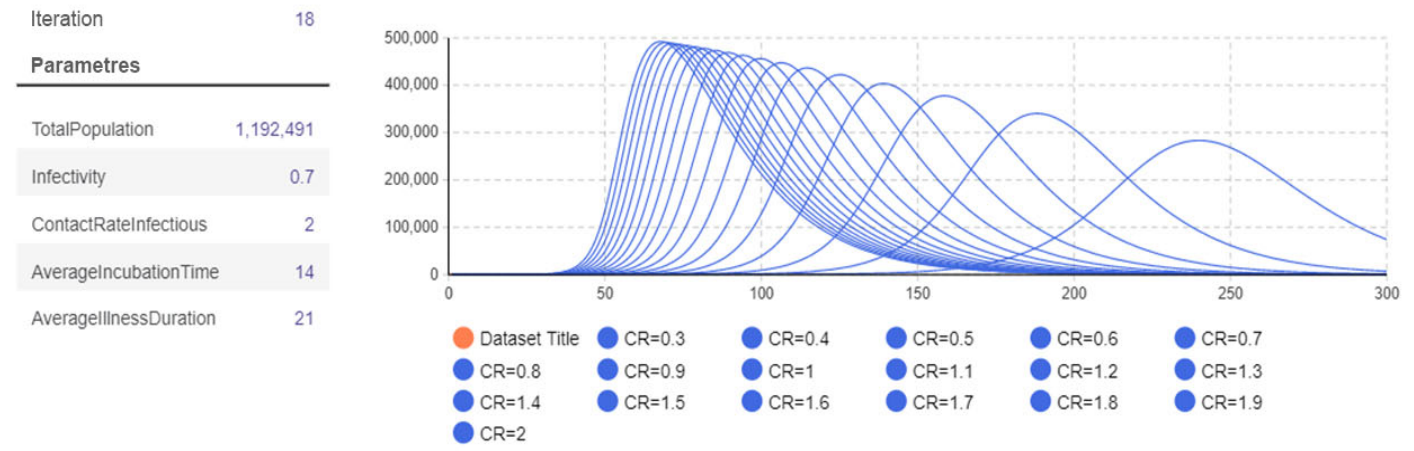

Figure 6. Experiment of parameters variation

As a result, a series of model runs with different values of ContactRateInfectious parameter is performed and the results of each run are added to the graph.

The results of the experiment of varying the parameters show that with a higher intensity of contacts between people, the infection spreads faster, which proves the initial assumption about the behavior of the virus.

During the experiment, 18 iterations were performed for different values of ContactRateInfectious parameter in the range from 0.3 to 2 , and the graph, respectively, shows 18 different scenarios for the infection spread.

The implemented model of the epidemic spread exactly reflects the modeled process. But some parameter values cannot be measured accurately. To implement the most reliable model, you should validate the values of Infectivity and ContactRateInfectious parameters. With the help of historical observations taken from real life, it is possible to calibrate the values.

The calibration experiment runs the model many times and compares the totals of each run to historical values. As a result, the system will select the values at which the simulation results are the most similar to the real ones [6-12].

For the calibration experiment, historical data are initially added to the model (Figure 7): daily measurements of the number of sick individuals.

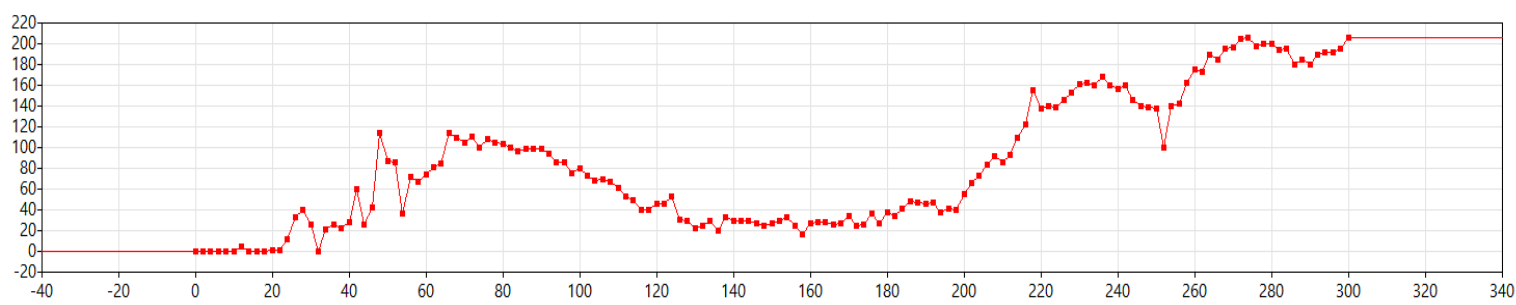

Figure 7. Graph of the dynamics of the epidemic spread in the Bryansk region

The idea is to reduce the difference between the simulation results and historical data. For this purpose, the least squares method is used. The results of running the experiment are shown in Figure 8.

As a result, there is a selection of the most suitable results, with which we get the most accurate simulated situation, close to the reality.

After this experiment, a model with calibrated parameters should be run for further study of the situation and drawing conclusions.

Based on the initial model shown in Figure 2, we can say that most of the population is infected with the virus, but not everyone will get sick. Carriers of the disease that have immunity are about $30 \%$ of the number of infected people. Mortality is $5 \%$ of the number of infected, respectively, $95 \%$ will be cured. If we believe the model, then by the 250th day there will be no infected people, and the number of recovered people will be $100 \%$, therefore, the pandemic will stop. 


\begin{tabular}{|c|c|c|}
\hline & Current & Best \\
\hline Iteration & 504 & 331 \\
\hline Functional & 46.662 & 45.714 \\
\hline Parametres & & Copy best \\
\hline TotalPopulation & $1,192,491$ & $1,192,491$ \\
\hline Infectivity & 0.486 & 0.293 \\
\hline ContactRatelnfectious & 0.382 & 0.659 \\
\hline AveragelncubationTime & 14 & 14 \\
\hline AveragelllnessDuration & 21 & 21 \\
\hline Fatality & 0.05 & 0.05 \\
\hline
\end{tabular}
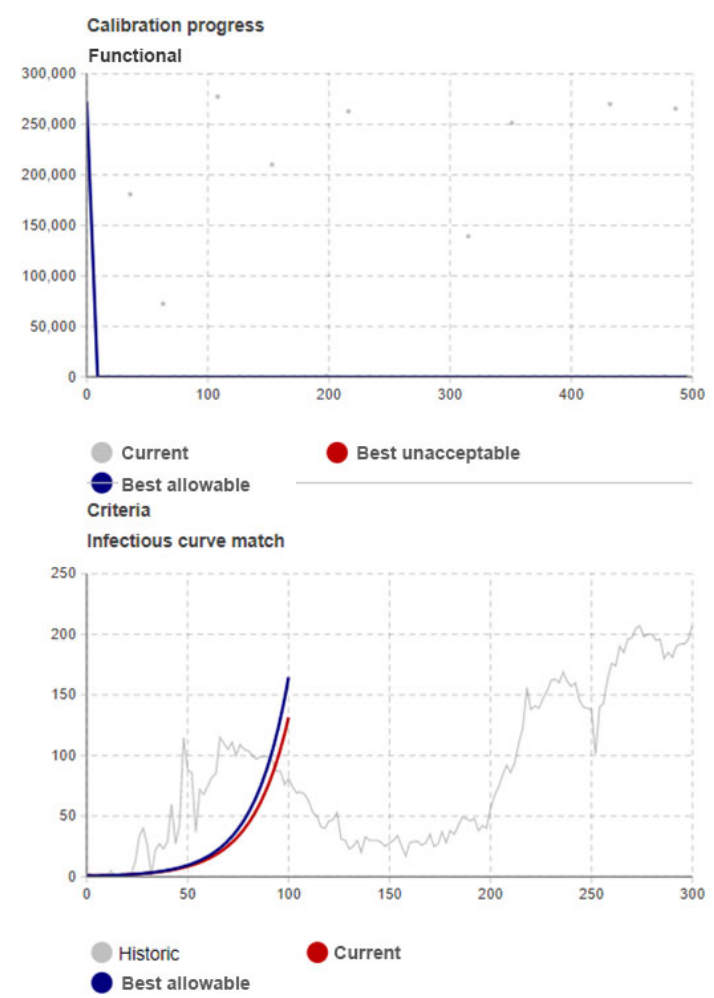

Figure 8. Results of the experiment of values calibration

But the calibrated model is very different from the originally built one. Based on the historical data of the disease, it turns out that the carriers of the disease who have immunity are about $5 \%$ of the number of infected, and not $30 \%$. The mortality rates and the number of those who are cured coincide (mortality $-5 \%$, cured-95\%). But the day of the end of the pandemic shifts from the 250th day to the 450th.

\section{Conclusions}

In this paper, the system dynamics approach was used to develop a model for the epidemic spread.

The project was visualized according to the process modeling, in which the storage devices are the categories of people that are important for the process under study, and the parameters are the main features of COVID-19 virus, connected by data flows with specified formulas.

As a result of the created model, two experiments were conducted: an experiment of varying the parameters, where it was found that with a higher rate of contacts between people, the infection spreads faster, and a calibration experiment, where historical data on the epidemic spread were collected and applied to the model, thereby bringing the values closer to the reality.

Thanks to the flexibility and powerful arsenal of AnyLogic system, it is possible to simulate complex systems and collect relevant information about the simulated system, which allows to determine the behavior of the system in reality approximately. But the only drawback of designing models is that it is impossible to take into account all the effects, both external and internal, on the system being modeled. When implementing this work, the number of isolated and hospitalized people was not taken into account, as well as the fact of vaccination of the population. But, despite this, we have obtained a model of events, which almost corresponds to the true model.

As a result of modeling, it is also possible to collect the necessary information about the simulated system, which allows to clearly demonstrate the spread of infection, as well as to predict the rationality or irrationality of the designed system, and identify ways to solve problems. 


\section{References}

[1] E. V. Efromeeva, Simulation modeling: fundamentals of practical application in AnyLogic, Vuzovskoe obrazovanie, Saratov, 2020, p. 120.

[2] S. N. Chernyaeva, Simulation modeling of systems, Voronezh State University of Engineering Technologies, Voronezh, 2016, p. 96.

[3] O. V. Limanovskaya, Simulation modeling in AnyLogic 7. Part 1, Publishing House of Ural University, Ekaterinburg, 2017, p. 152.

[4] COVID-19, New Coronavirus Infection, TOPC-KoB-2. URL: https://www.krasotaimedicina.ru/diseases/ infectious/.

[5] Coronavirus: Statistics. URL: https://yandex.ru/covid19/stat?utm_source=main_notif\&geoId=10 650 .

[6] Text book on modelling in AnyLogic TM. Copyright XJ Technologies, 2005.

[7] Leonov YU A, Leonov E A, Kuzmenko A A, Martynenko A A, Averchenkova E E, Filippov R A, Selection of rational schemes automation based on working synthesis instruments for technological processes, Yelm, WA, USA: Science Book Publishing House LLC, 2007.

[8] F. YU. Lozbinev, A. S. Sazonova, L. B. Filippova, Prognozirovaniye zhivuchesti korporativnoy seti svyazi na osnove neyro-nechetkogo podkhoda (Virtual'noye modelirovaniye, prototipirovaniye i promyshlennyy dizayn, Materialy IV Mezhdunarodnoy nauchno-prakticheskoy konferentsii (2017), Tambovskiy gosudarstvennyy tekhnicheskiy universitet.

[9] R. A. Filippov, Internet veshchey i obespecheniye bezopasnostiv(Mezhdunarodnaya nauchnoprakticheskaya konferentsiya "Innovatsii v promyshlennosti, upravlenii i obrazovanii", Bryansk, BGTU, 2017, pp. 76-78

[10] A. A. Kuz'menko, D. Ye. Kondrashin, Metody i podkhody k razrabotke sistemy avtomatizirovannogo analiza dinamiki izmeneniya ploshchadi lesnykh nasazhdeniy na osnove metodov avtomaticheskogo raspoznavaniya obrazov, Bryansk. ERGODIZAYN 6 (2019) 230-240.

[11] R. A. Filippov, L. B. Filippova, A. S. Sazonova, Internet veshchey: osnovnyye ponyatiya, BGTU, Bryansk, 2016.

[12] E. A. Leonov, Y. A. Leonov, Y. M. Kazakov, L. B. Filippova, Intellectual Subsystems for Collecting Information from the Internet to Create Knowledge Bases for Self-Learning Systems, Proceedings of the Second International Scientific Conference "Intelligent Information Technologies for Industry" (IITI'17). IITI 2017. Advances in Intelligent Systems and Computing, volume 679 (2018) 94-103. 